\title{
The Impact of the Nagoya Protocol on Science
}

\author{
David Smith* \\ Biomedical Engineering, UK
}

Submission: December 12, 2017; Published: April 10, 2018

*Corresponding author: David Smith, Biomedical Engineering, CABI, Bakeham Lane, Egham, Surrey TW20 9TY, UK, Email: d.smith@cabi.org

\section{Background}

Users of biological materials equating to genetic resources have responsibilities in the fair and equitable sharing of benefits arising from their use. The Nagoya Protocol on access to genetic resources and the fair and equitable sharing of benefits arising from their utilization https://www.cbd.int/abs/ is a 2010 supplementary agreement to the 1992 Convention on Biological Diversity. Nations were invited to ratify this and implement regulation to enforce it. The Nagoya Protocol entered into force on 12 October 2014. In Europe, the EU Regulation on Access and Benefit Sharing (ABS) was enacted simultaneously [1]. This was followed by European nations implementing their regulation, striking a balance between regulatory control and due diligence. Each country signatory to the CBD and the Nagoya Protocol will implement its own controls, ensuring compliance with its requirements. In December 2017 there were 101 Parties to the Protocol with 50 countries publishing regulation on the ABS Clearing House https://absch.cbd.int/ Each scientist and all organisations must align their practices in the conservation and use of genetic resources (GR) in all their projects to comply globally with the Nagoya Protocol on ABS requirements, as well as working within the spirit of the CBD.

The main premise of the Nagoya Protocol is:

a. To prevent the utilisation of genetic resources, or associated traditional knowledge, which were not accessed in accordance with the national access and benefit-sharing legislation or regulatory requirements of a Party to the Nagoya Protocol

b. To support the effective implementation of benefitsharing commitments set out in mutually agreed terms between providers and users

c. to improve the conditions for legal certainty in connection with the utilisation of genetic resources and traditional knowledge

The Protocol is impacting on research requiring the researcher to seek permission to access genetic resources in advance of collection and thus in the project planning stage. They must negotiate mutually agreed benefits that will be shared from the intended use. Smith et al. [1] describe how this impacts on microbiology and provide a decision true to help scientists comply with ABS requirements [2]. Many signatories to the Protocol are only just putting in place specific measures to implement the Nagoya Protocol making it difficult to get the information needed for compliance. Scientific communities are developing best practice much of which is published on the ABS Clearing House https://absch.cbd.int/search/ referenceRecords?schema=modelContractualClause.

\section{Conference of the Parties (COP-MOP) Evaluation of} the Effectiveness of the Nagoya Protocol October 2017

The Conference of the Parties issued a notification: Contribution to the first Assessment and Review of the Effectiveness of the Nagoya Protocol Ref.: SCBD/SPS/ DC/VN/BG/JR/86908https: //www.cbd.int/kb/record/ notification $/ 2679$ ? RecordType=notification $\&$ Subject $=$ ABS

The purpose of this notification was to collect information on:

(a) The use of model contractual clauses, codes of conduct, guidelines, best practices and/or standards as well as indigenous peoples and local communities customary laws, community protocols and procedures; and (b) the implementation and operation of the ABS Clearing-House. The Centre for Agriculture and Biosciences International (CABI) responded. CABI is an international not-for-profit organization that uses genetic resources in its mission to improve people's lives by providing information and applying scientific expertise to solve problems in agriculture and the environment (www.cabi.org/). This is achieved through knowledge sharing and the application of scientific research to improve global food security and safeguard the environment. In doing so CABI accesses biological and genetic resources and undertakes sampling/collection of biological materials and delivers benefits to farmers around the world through its mission-driven activities by helping them grow more and lose less of what they produce. CABI's aims in the use of biological and genetic resources of plant, animal or microbial origins are to engender trust to facilitate science and to ensure that benefits are shared. 
CABI has prepared and is implementing policy on Access and Benefit Sharing (ABS) and works with its partners and various relevant communities to introduce best practice in compliance with country requirements. CABI has introduced a generic material Transfer Agreement to ensure recipients of genetic resources from CABI are aware of their responsibilities in the use of genetic resources and any benefit-sharing commitments made. CABI is in the process of negotiating access with all provider countries of genetic resources that are used in the course of CABI's work. These documents are shared with partners but as yet have not been made public. CABI is aware of several community model contractual clauses, codes of conduct, guidelines, best practices and/or standards in relation to access and benefit-sharing which it takes into consideration; for example:

a. European Culture Collections' Organisation (ECCO) core MTA https://www.eccosite.org/ecco-core-mta/

b. Microbial Resources Research Infrastructure (MIRRI) ABS Manual https://zenodo.org/record/284881

c. Global Genome Biodiversity Network (GGBCN) ABS Guidance, Best Practice for ABS: http://www.ggbn. org/docs/ABS_Guidance/GGBN\%20Guidance\%20_Best_ Practice_June_2015-Final.pdf

d. International Organisation for Biological Control of Noxious Animals and Plants (IOBC) Commission on Biological Control and ABS http://www.iobc-global.org/ global_comm_bc_access_benefit_sharing.html

e. Consortium of European Taxonomic Facilities (CETAF) Code of Conduct and Best practices https://cetaf.org/sites/ default/files/final_cetaf_abs_coc.pdf

Information is often difficult to access and not always available on the ABS Clearing House, making it necessary to contact the appropriate National Focal Point (NFP) or a Competent National Authority (CNA). CABI believes that more centralised help could be offered. Researchers who wish to access a country's genetic resources are asking the same questions of the national authorities regarding the processes for compliant access which are most often not transparent and easily accessible. Answers to frequently asked questions and details of process and when they are triggered would be most helpful. So much time is lost retrieving information from the National authorities, surely processes to reduce administrative burden are possible. There are potentially 198 parties to the Nagoya Protocol each with their own ABS requirements, bringing the practical guidance and information necessary for compliance should not be beyond COP and it would save a tremendous amount of wasted time and duplicated effort [3].

In the process of negotiating access and use of microorganisms and invertebrates for CABI's specific uses CABI has contacted 28 countries; 10 have said that they have no current access controls and they were happy for CABI staff to collect and use as per our policy; one country, Ghana, has signed an Memorandum of understanding based upon the implementation of CABI Policy; one country just commented that "we have law, follow it". However, negotiations continue with 12 countries and we have failed to establish communication with 4 of them. The reasons for this are many mainly those countries are still trying to decide what they want or are currently drafting regulation. There are several common factors in responses each presenting difficulties:

a. Work through in-country partners; for CABI this is relatively easy as we work through country partnerships but for many it is not so easy to find appropriate partners

b. Deposit samples in-country; many countries do not have the collections nor the capacity

c. Deliver CABI benefits; the appropriate and equitable level of benefits is not consistent between countries

d. Implement best practices in a transparent way; monitoring and reporting mechanisms are often quite burdensome

e. Obey the law - obviously but it is not always easily accessible (physically and in a language we can understand) and what are the mechanisms and practical steps that must be followed; these are rarely defined in the regulation itself.

\section{Will Controls Extend to Digital Sequence Information}

They continues to be debate on whether access to Digital Sequence Information (DSI) should be treated in the same way as accessing the genetic resource or material (organism) itself https://www.cbd.int/abs/dsi-gr.shtml. It is obvious they are not the same thing, as you are able to do more with the organism than you can with a partial sequence or even an entire genome. $16 \mathrm{~S}$ ribosomal DNA for bacteria and similarly ITS for eukaryotes, have been the basis of modern taxonomy and in the future, whole genome sequencing will impact even more. The benefits of such genome datasets are likely to be much larger once the analysis is at the same speed as the generation of the data. However, generating and publishing sequence data is considered by many to be descriptive information and is therefore not utilisation and would accordingly be out of regulatory scope. Publishing the sequence as electronic data should be considered an act of benefit sharing. The EU and countries have submitted opinion on this topic and it continues to be important that scientists contribute to help reach a practical and implementable solution. DSI needs to be freely shared in the public domain to help address the taxonomic impediment that the CBD recognises, and to meet the needs of agriculture and science.

\section{Complying with the Nagoya Protocol on Access and Benefit Sharing}

The EU Regulation (no. 511/2014) on ABS compliance does not address access to genetic resources this is left to the individual states each able to take its own approach with France 
and Spain electing to control access whilst the UK and others opting not to put access controls in place. The EU Regulation applies to genetic resources:

a) from countries that exercise sovereign rights

b) when countries have established applicable access measures and ratified the Nagoya Protocol

c) that were accessed after 12 October 2014 [Or if later the date of enactment of national legislation]

d) that are not already governed by specialised international instruments

Researchers must ask key questions to understand if they need to take action in order to comply. Where does the material originate from, does the country control access? When the genetic resources collected and are they in scope? The EU regulation is applicable when conducting research and development on the genetic and/or biochemical composition of genetic resources, including through the application of biotechnology. Information on country requirements can be found at the ABS Clearing House https://absch.cbd.int/. Exactly what uses require benefit sharing is still under discussion and differs from country to country. Some actions are considered simply observations and don't trigger the Nagoya Protocol e.g. identification/taxonomy but this depends on the provider country. Due diligence requires confirmation of country requirement often needing consultation with country National Focal Points or Competent National Authorities [3]. Countries controlling access require the collector and user to negotiate mutually agreed terms having sought prior informed consent to the regulator. Checkpoints are being introduced in Europe due diligence declarations are needed when:

a. Securing funding for research and development on genetic resources

b. A product goes to market Guidance has been issued to facilitate compliance:http://eur-lex.europa.eu/legal-content/ EN/TXT/?uri=CELEX\%3A52016XC0827\%2801\%29andsector specific guidance is being drafted for e.g. Biotechnology;
Food and Beverage; Bio-control and Bio-stimulants; Cosmetics; Researchers; Culture Collections etc. Due diligence declarations can be submitted electronically and information and guidance given in the UK through the UK Regulatory Delivery Department for Business, Energy and Industrial Strategy (BEIS) https://www.gov.uk/guidance/ abs. See your national focal points and competent national authorities https://absch.cbd.int/countries for information on compliance the last thing you would wish to do is spoil research relationships with other countries. Find your national stakeholders group and ensure you contribute to implementing practical and implementable compliance procedures.

\section{Acknowledgement}

This work received the support of the CABI Development Fund (with contributions from the UK's Department for International Development, the Australian Centre for International Agricultural Research and others). CABI is an international intergovernmental organisation and we gratefully acknowledge the core financial support from our member countries (and lead agencies) including the United Kingdom (Department for International Development), China (Chinese Ministry of Agriculture), Australia (Australian Centre for International Agricultural Research), Canada (Agriculture and Agri-Food Canada), Netherlands (Directorate-General for International Cooperation) and Switzerland (Swiss Agency for Development and Cooperation). See https://www.cabi.org/ about-cabi/who-we-work-with/key-donors/ for full details.

\section{References}

1. http://eur-lex.europa.eu/legal-content/EN/TXT/?uri=CELEX:32014R0511

2. http://mic.microbiologyresearch.org/content/journal/micro/10.1099/mic. 0.000425

3. Beckett K (2017) Understanding Access and Benefit Sharing. The Biologist 64: 26-27.

\begin{tabular}{l} 
Your next submission with Juniper Publishers \\
will reach you the below assets \\
- Quality Editorial service \\
- Swift Peer Review \\
- Reprints availability \\
- E-prints Service \\
- Manuscript Podcast for convenient understanding \\
- Global attainment for your research \\
- Manuscript accessibility in different formats \\
( Pdf, E-pub, Full Text, Audio) \\
- Unceasing customer service \\
Track the below URL for one-step submission \\
https://juniperpublishers.com/online-submission.php \\
\hline
\end{tabular}

